\title{
Deslocando as relações de gênero: infâncias e candomblé, contribuições para a educação com crianças pequenas
}

Resumo: $O$ presente artigo tem como objetivo apresentar parte dos dados da tese de Souza (2016), intitulada Experiências de infâncias com produções de culturas no llê Axé Omo Oxélbálatan, em diálogo com os estudos feministas de Louro (2008), Hooks (2013) e Daves (2016) e a perspectiva das pesquisas descoloniais de Quijano (2005) e Santos (2010), que rompem com uma perspectiva eurocêntrica, binária e cartesiana das relações de gênero. Destacamos a perspectiva de mundo "yorubá" quanto à questão de gênero como uma conjunção quartenária de princípios, cuja sintaxe organiza as categorias "aborô", correspondente ao princípio masculino; "iyabá", ao feminino; "metá-metá", o que circula simultaneamente pelos dois primeiros, e "laíibalopô", o que se coloca para fora e além de qualquer perspectiva sexual e de gênero, diferente, contudo, da categoria "assexuado", de matriz ocidental. Entretanto, constatou-se que mesmo em um espaço que subverte a perspectiva colonizada das relações de gênero em sua cosmologia, as crianças apresentam práticas que travam relações binárias que associam o feminino a aspectos de subalternidade e reservam ao masculino aspectos de superioridade. Em função disso, esse discurso termina por legitimar as mesmas características historicamente atribuídas ao feminino (delicadeza, fragilidade, inferioridade, etc.), como se o masculino estivesse ligado à cultura e o feminino à natureza. Considerando as experiências de infâncias no candomblé, com inspirações na lógica exúlica, descrita por Souza(2016), e na Pedagogia Macunaímica de Faria (2002), apresentam-se algumas possibilidades para a construção de pedagogias descolonizadoras para a educação com crianças pequenas.

Palavras-chave: Gênero. Infâncias. Candomblé.

\section{Shifting gender relations: childhood and candomblé, contributions to education with young children}

Abstract: The present work aims to present part of the data of the tesis of Souza (2016), entitled "Experiences of childhoods with production of cultures in llê Axé Omo OxélbáLatan", in a dialogue with the feminist studies of Louro (2008), Hooks (2013) and Daves (2016) and the perspective of the decolonial researches of Quijano (2005) and Santos (2010) that break with a Eurocentric, binary and Cartesian perspective of gender relations. Weemphasize the Yoruba world view on the question of gender as a quaternary conjunction of principles, whose syntax organizes the categories "aborô", corresponding to the masculine principle; "iyabá", to the feminine; "Metá-metá", which circulates simultaneously by the first two, and "laíibalopô", which stands out and beyond any sexual and gender perspective, but different from the "asexual" category of the Western matrix. However, it has been foundt hateven in a space that subverts the colonized perspective of gender relations in their cosmology, children present practices that bindbinary relations that associate the feminine with aspects of submission and reserve the masculine aspects of superiority. As a result, this discourse endsuplegitimizing those same characteristics historically attributed to the feminine

'Doutora em Educação. Professora Universidade Federal de Lavras. E-mail: ellenl.souza@ded.ufla.br

2Doutor em Antropologia. Professor de Antropologia na Universidade da Integração Internacional da Lusofonia Afro-Brasileira (UNILAB). Membro do grupo Laroyê Culturas Infantis e Pedagogias Descolonizadoras. E-mail:patricio.carneiro@gmail.com 
(delicacy, fragility, inferiority, etc.), as if the masculine was linked to the culture and the feminine to the nature. Considering childhood experiences in Candomble, with inspiration in the exuliclogic described by (Souza, 2016) and the Pedagogia Macunaímica (Faria, 2002), some possibilities for the construction of decolonizing pedagogies for education with young children are presented.

Keywords: Gender. Childhoods. Candomblé.

Introdução

Digo: o real não está na saída nem na chegada: ele se dispõe para a gente é no meio da travessia Guimarães Rosa (Grandes Sertões Veredas)

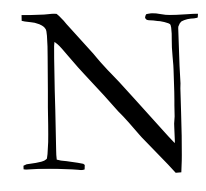

osso artigo, intitulado Deslocando as relações de gênero: infâncias e candomblé, contribuições para a educação com crianças pequenas, começa no gerúndio, indicando uma ação contínua, ou seja, uma forma verbal que não possui flexão de tempo e modo. Assim, inspirados em uma perspectiva freireana de educação, em que "O mundo não é, o mundo está sendo [...]" (FREIRE, 1997, p. 100). O nosso compromisso está com a construção, as inquietações coletivas da atualidade e com as brincadeiras das crianças do candomblé.

E neste mundo que está sendo, no ir e vir dos marcos jurídicos educacionais, cabe marcar posição em relação à decisão do Supremo Tribunal, em setembro de 2017, quando ficou estabelecida a permissão do ensino religioso confessional ${ }^{3}$ em escolas públicas. Tal permissão abre mais espaço para as violências contra a cosmologia afro- diaspórica, que, em sua estrutura, apresenta bases matriarcais, reconhecendo a multiplicidade de gêneros e compreendendo as diferentes orientações sexuais.

Conforme destaca Araújo (2017), a intolerância religiosa está presente nas escolas públicas, mas o que estrutura tal intolerância é o ataque à herança cultural africana e afro-brasileira.

Selecionamos o candomblé como fonte para orientações na construção de uma educação igualitária, para colaborar como aporte para a construção de uma educação para e nas relações étnicoraciais, conforme estabelecido pela Lei de Diretrizes e Bases da Educação Nacional, alterada pela Lei 10.639/03, que estabelece a obrigatoriedade do ensino de História e cultura africana e afro-brasileira na Educação Básica. Nesse sentido, convém retomar uma descrição de candomblé, elaborada pelo famoso etnólogo Pierre Verger. Segundo ele:

${ }^{3}$ Cabe destacar que o candomblé não tem por perspectiva o proselitismo, ou seja, essa seria uma desvantagem diante de religiões cristãs que têm essa prática e poderiam fazer uso do recurso de conversão para a evangelização nas escolas. 
Candomblé é o nome dado na Bahia às cerimônias africanas. Ele representa, para seus adeptos, as tradições dos antepassados vindos de um país ${ }^{4}$ distante, do alcance e quase fabuloso. Trata-se de tradições mantidas com tenacidade, e que lhes deram a força de continuar sendo eles mesmos, apesar dos preconceitos e do desprezo de que eram objetos suas religiões, além da obrigação de adotar a religião dos seus senhores.

O candomblé torna-os membro de uma coletividade familiar, espiritual, para a qual estão atavicamente preparados. Essa forma de organização social proporcionava-lhes uma segurança e uma estabilidade que nem sempre reencontraram em nossa civilização (VERGER, 1999, p.24).

Segundo essa perspectiva, "candomblé" tanto é o conjunto de cerimônias que ritualizam a vida das pessoas ligadas a essas comunidades, quanto sua forma de ser e estar no mundo. Ser de candomblé é assumir um ethos que transcende as formas mais corriqueiras e ocidentais de ser e estar no mundo, já que o candomblé tem como principais referências as experiências afro-diaspóricas daquelas populações que tiveram que refazer e ressignificar suas formas de existência e de construir sentidos na diáspora. Nesse processo de reconstruir suas estruturas de sentido, também teve que ressignificar os parâmetros de entendimento acerca de orientação sexual, identidades de gênero, modelos familiares, etc.

No contexto desta nossa reflexão, também convém explicitar a unidade básica da organização social e de convivência na qual vivem as populações de candomblé. Neste sentido, há que se fazer referência ao espaço privilegiado no qual se dão as principais experiências de vivências desse povo. Indiscutivelmente, o terreiro constitui o espaço privilegiado das múltiplas vivências dessa população. É ali que o povo de santo (ou povo de axé, ou povo de candomblé, ou, ainda, povo de terreiro) vive, ama, sente, constrói suas referências e engendra sentidos para sua existência. Portanto, para esse povo, falar da forma de ser e estar no mundo é falar da importância do terreiro.

De fato, é no terreiro onde ocorrem os diferentes embates que constroem ou reconstroem os parâmetros de relações múltiplas que compõem a existência. Não é à toa que o filósofo negro brasileiro Muniz Sodré, em seu clássico estudo O Terreiro e a cidade (1988), referiu-se ao terreiro como "A forma social negro-brasileira".

A respeito do terreiro e sua importância para o povo de candomblé, Muniz Sodré afirmou:

As comunidades litúrgicas conhecidas no Brasil como terreiros de culto constituem exemplo notável de suporte territorial para a continuidade da cultura do antigo escravo em face dos estratagemas simbólicos do senhor, daquele que pretende controlar o espaço da cidade. Tanto para os indígenas como para os negros vinculados às antigas cosmologias africanas, a questão do espaço é crucial na sociedade brasileira (ao lado dela, em grau de importância, só se coloca a questão da força, do poder de transformação e realização, que perpetua a dinâmica da vida). Mas essa não é uma questão exclusiva de determinados segmentos étnicos. Para todo e qualquer indivíduo da chamada "periferia colonizada" do mundo, a redefinição da cidadania passa necessariamente pelo remanejamento do espaço territorial em todo o alcance dessa expressão. (SODRÉ, 1988, p. 18).

É possível verificar pelas palavras de Sodré algumas categorias que estão estreitamente relacionadas com a discussão aqui apresentada: território, cidade, periferia colonizada e redefinição da cidadania são categorias que compõem um campo semântico relacionado com o fazer, o desfazer e o refazer das 
identidades afro-diaspóricas, inclusive aquelas que se referem às identidades e relações de gênero. Assim, ao pensarmos os deslocamentos das relações de gênero observados entre essa população, é indispensável considerar as vivências estabelecidas no terreiro, já que é o espaço onde essas disputas começam e onde se definem as diferentes leituras e os parâmetros das categorias incorporadas às vivências pessoais e coletivas, no que se refere às vivências da sexualidade e das identidades de gênero.

Além disso, a experiência afro-diaspórica impõe às populações africanas e descendentes de africanos condições de vida que, de certa forma, criam um ambiente propício à redefinição das relações e identidades de gênero e a novas compreensões de vivência da sexualidade. Os estudos acerca de territórios negros urbanos 5 , por exemplo, discutem situações que impõem às populações negras urbanas uma contiguidade que redefine a forma de se relacionar, inclusive com o espaço. No calor da vida cotidiana citadina, as diferentes vivências que envolvem tanto os espaços sagrados quanto os "profanos", numa simbiose que possibilita um clima de elasticidade favorável à desconstrução de certas fronteiras que, em África, se mostravam deveras rígidas e que na diáspora não serão mais tão rígidas assim.

Raquel Rolnik, por exemplo, ao estudar os territórios negros nas cidades de São Paulo e Rio de Janeiro, reconhece a importância do terreiro como território no qual as populações negras brasileiras vivenciam importantes experiências existenciais na diáspora. A pesquisadora, contudo, ao se referir aos terreiros de culto, faz questão de chamá-los de "terreiros religiosos", já que, em sua análise, as comunidades negras sempre se referiram a espaços coletivos como terreiros. Assim, ao tratar do espaço reservado ao culto, a autora sempre acrescenta o qualificativo "religioso", a fim de diferenciar esse espaço das outras formas de terreiros, dentre eles o de samba. Ao tratar dos territórios negros da Barra Funda e Campos Elíseos - região a qual ela chama de "o território mais caracterizadamente negro de São Paulo" nas primeiras décadas do século XX, assim ela se refere:

Berço do samba paulista, ali se localizavam clãs africanos urbanos, nos cortiços e casinhas. O terreiro, espaço sagrado-profano que poderia ser o lugar do culto ou da macumba, mas também o lugar da roda de samba e da vida cotidiana, era formado pelo pátio ou corredor do cortiço e os quintais das casas. Eram pequenos espaços de interação social, onde as classes e etnias subalternas se esforçavam pela apropriação de alguma parte do produto social - emprego eventual, os negócios, os biscates - e como pela apropriação do espaço social, em busca de um lugar próprio na cidade. (ROLNIK, 2003, p. 77).

Verifica-se, com as palavras de Rolnik, o quanto as vivências da população negra brasileira eram marcadas por interconexões entre o sagrado e o profano, ambos sempre juntos, simbióticos e indissociáveis. Essas interconexões se dão em todos os âmbitos da vida, já que é justamente no espaço do território (aqui representado de forma privilegiada pelo terreiro - seja ele reservado às práticas de

\footnotetext{
${ }^{5} \mathrm{~A}$ esse respeito cf: VELHO, Gilberto. Antropologia e patrimônio cultural. Revista do Patrimônio Histórico e Artístico Nacional. Nº 20 , 1984, p. 37-39.

SILVEIRA, Renato da.O candomblé da Barroquinha: processo de constituição do primeiro terreiro baiano de ketu. Salvador: Edições Maianga, 2006.

${ }^{6}$ Deve-se advertir o leitor e a leitora de que essa dicotomia sagrado-profano - que já foi objeto de muitos estudos, dentre os quais o de MiceaEliade, é referência obrigatória - muito mais do que um simples binômino heurístico, e constitui um dos mecanismos de leitura do mundo mais ocidentais do que africanos. Nesse sentido, aqui recorremos a ele simplesmente para sermos mais inteligíveis na nossa reflexão. Contudo, advertimos que nas culturas africanas e afro-diaspóricas nem sempre esse binômio é eficaz para explicar o mundo e as formas de ritualizar a existência, já que nessas culturas não há uma separação estanque entre o sagrado e o profano, como é concebido no Ocidente.
} 
ritualização religiosa da vida ou não) que são desconstruídas, reconstruídas, reelaboradas e ressignificadas as referências existenciais, inclusive aquelas relacionadas à vivência tanto da sexualidade quanto das identidades de gênero.

No que se refere ao espaço do terreiro religioso, dessas leituras emerge uma compreensão acerca da continuidade existente entre o mundo dos ancestrais e dos seres humanos vivos, chamando sempre a atenção para o fato de que a existência se constitui tanto de uma existência visivel (histórica), quanto de uma existência invisivel (memória), conforme a análise feita por Fábio Leite (2008). Nessa perspectiva, o invisível convive em contiguidade com o visível, constituindo uma realidade indivisível.

O indivisível, por sua vez, não é uno, mas múltiplo. Essa é uma das referências herdadas das culturas africanas que originaram a forma afro-diaspórica de ser e estar no mundo. E, justamente por isso, as estruturas de sentido que caracterizam a vida do povo de candomblé acompanham a compreensão africana de significar a existência. Em última análise, a reconstrução do mundo na diáspora respeita e obedece a certas estruturas africanas de organizar a vida - mesmo que as transcendam, e muito, em determinados campos, como é o caso da sexualidade e das identidades de gênero, conforme será explanado adiante.

Já se sabe que o continente africano compreende diversas tradições e não podemos tratá-las como uma única tradição. É justamente isso que se pode verificar nos processos de reconstrução das identidades africanas na diáspora e da construção dessas novas identidades afro-diaspóricas que implicam, inclusive, um repensar das categorias de orientação sexual e identidade de gênero. Há, então, nas culturas afrodiaspóricas, rupturas e continuidades em relação às referências africanas que as originaram. HampatêBâ (2003, p.1) ressalta, entretanto, que há grandes constantes como “[...] a presença do sagrado em todas as coisas, a relação entre o mundo dos vivos e o mundo dos mortos, o sentido comunitário, o respeito religioso pela mãe". Veremos mais adiante como, nesse campo do que HampatéBâ chama de "presença do sagrado em todas as coisas", localiza-se a forma de se vivenciar a sexualidade e de lidar com as identidades de gênero. Assim, as formas de classificar as categorias sexuais e as identidades de gênero serão fortemente marcadas e determinadas pelas experiências religiosas do povo de candomblé.

No que diz respeito às categorias de orientação sexual e identidades de gênero, construídas na diáspora, essas "rupturas" serão chamadas de "deslocamento de relações de gênero". Os deslocamentos das relações de gênero, quando se pensa a população de candomblé, serão fundamentados e explicados a partir de uma mitologia que, na verdade, constitui a base mais sólida das explicações de toda a experiência existencial dessas populações. Nesse sentido, todas as possíveis construções de sentido que dizem respeito à vivência da sexualidade ou das identidades de gênero encontrarão uma fundamentação religiosa, descartando qualquer forma de rejeição, discriminação ou negação. Tudo isso, porém, existe no mundo dos terreiros, conforme será apresentado mais adiante nas conversas de um grupo de crianças; contudo, qualquer forma de discriminação deverá ser atribuída mais a influências cristãs e ocidentais do que às próprias vivências desse povo. 
Nosso objetivo é, então, conforme já anunciado, analisar esses deslocamentos das relações de gênero que se dão no mundo dos terreiros, chamando sempre a atenção para o fato de que todas as possibilidades de vivência da sexualidade e das identidades de gênero, longe de serem consideradas patologias, desajuste psíquico-social ou qualquer forma de estigmatização, são, na verdade, compreendidas a partir de uma visão sagrada da existência. E, nesse sentido, a personalidade das divindades - descritas nas mitologias - é a referência mais imediata das explicações para essas múltiplas possibilidades.

\section{Vivenciando com crianças um terreiro}

Para começar nossa análise, destacamos um dos episódios registrados na tese de Souza (2016, p. 150-51), intitulado "O destino da religião com gênero e sexualidade". É com as palavras das crianças coletadas enquanto construíam culturas, no Ilê Axé Omo OxéIbá Latam7, que almejamos refletir a respeito de nossas compreensões de gênero e sexualidade e como estas atravessam as experiências no candomblé.

Iago e Pedro conversam no sofá da sala de jogos 8 , enquanto no barracão os santos estão tomando rum? . Quatro meninas, Gisele, Luara, Lorena e Luísa brincam com as bonecas sentadas no tapete, e no canto da sala uma ekede ${ }^{10}$ trabalha acordando um filho de santo do transe.

Pedro - Vamos brincar com as meninas e as bonecas?

Iago - Eu não, não sou "viado"! Você é "viadinho" (risos)

Pedro - Claro que não, eu sou oga a $\tilde{a}^{11}$ de Xangôo ${ }^{12}$ !

Iago - E dai?

Pedro - Não existe ogã viado! Ogã tem que ser homem!

Iago - Mas, você quer brincar de boneca, é menininha (risos)

Pedro - Você que vai ser "viado", porque não é ogã (risos) Você não é ogã, você não é ogã, é "viadinho"!

Iago - Chato!

Pedro corre atrás de Iago e solta o tablet. Em seguida, Luísa pega e filma as bonecas ${ }^{13}$.

Selecionamos esse episódio porque nos convoca a "gerundiar", desloca-nos em espaço e tempo, mostrando que as crianças começam, na brincadeira, a definirem suas respectivas funções religiosas a partir das suas concepções de gênero e sexualidade. Mas, é na circularidade dos saberes que as crianças interrogam a lógica do candomblé, contrapondo-a com o meio social em que vivem; as referências binárias de gênero e sexualidade ultrapassam os muros do terreiro e chegam sem serem convidadas.

Assim, as crianças definem a sexualidade e as potenciais orientações sexuais a partir de cargos demarcados na religião - em alguns casos específicos costumeiramente associados à determinada orientação sexual - e nos obrigam a repensar palavras previamente estabelecidas e as verdades tidas como absolutas.

\footnotetext{
${ }^{7}$ Nome da casa de candomblé liderada por Antônio Paulino de Andrade, conhecido como Toninho de Oxum, na zona Norte da capital paulista.

${ }^{8}$ Espaço: a parte do barracão que o babalorixá usa para atender às pessoas que vão consultar os búzios.

9 Rum: momento da festa pública do candomblé quando os iniciados em Orixá estão em transe dançando no barracão (considerado o ponto alto da festa).

10 Cargo feminino cuja responsabilidade é zelar pelo adepto que está em transe, dentre outras atividades religiosas. A esse respeito, recomenda-se a leitura de: BRANDÃO, Gersonice Equede Sinha. Equede: A mãe de todos - Terreiro Casa Branca. Salvador: Barabô, 2015.

11 Cargo masculino cuja responsabilidade está em auxiliar nos ritos internos e tocar as músicas religiosas.

12 Xângo, um dos orixás do candomblé, considerado masculino, cujo arquétipo representa a realeza e a governabilidade.

${ }^{13}$ Em Souza (2016), as crianças auxiliam a pesquisadora gravando suas brincadeiras com tablets.
} 
A conduta observada nas crianças em um momento de descontração, no Ilê Axé Omo OxéIbá Latam, nos instiga a repensar as relações estabelecidas nos espaços de vivências do povo de candomblé. Caso evoquemos a nossa condição de ex-colonizados, é possível constatar, além de todos os outros binarismos próprios da forma ocidental de ser e estar no mundo, aqueles binarismos já apontados e analisados por Georges Balandier, no seu texto A Noção de situação colonial (1993).

Segundo as palavras de Balandier, a noção de Situação Colonial envolve binarismos que, combinados, compõem a realidade de colonização. Entre as categorias que compõem esse conjunto de binarismos, o autor cita: sociedade colonial/sociedade colonizada, fatores internos/ fatores externos que caracterizam a situação colonial, dupla história, colonizado/colonizador, dominação/submissão, dominação política/dominação cultural, minoria numérica/minoria sociológica, nativos/estrangeiros, excelência do branco/inferioridade dos "outros", divisão étnica/divisão espiritual da sociedade colonizada, duplo poder, etc.

Ora, todos esses binarismos que caracterizam a situação colonial já refletem a forma dicotômica e maniqueísta do pensar ocidental. Essa mesma forma de pensar também condicionou as culturas e os povos que passaram pela experiência da colonização. As distâncias criadas por essas dicotomias e binarismos seriam explicadas por Boaventura de Souza Santos, por meio da metáfora do abismo, base para a construção de uma teoria acerca do chamado "pensamento abissal" (SANTOS, 2010). Nesse sentido, as identidades de gênero e as formas de vivenciar a sexualidade, por parte das sociedades não ocidentais, serão profundamente afetadas e influenciadas pela experiência da Situação Colonial. No candomblé, esses efeitos de longa duração poderão ser verificados na persistência de formas dicotômicas e binárias de encarar e vivenciar tanto a sexualidade quanto as identidades de gênero. E isso fica muito evidente naquela conversa das crianças no espaço interno (privado do terreiro).

A força do binarismo ocidental marcado na colonização ${ }^{14}$ expressa por Iago e Pedro desafia, inclusive, a cosmologia de mundo presente no candomblé. Assim, guardemos por um instante o diálogo da sala de jogos (espaço privado do terreiro) e vamos nos dirigir ao que acontecia simultaneamente ao som dos atabaques no barracão (espaço público do terreiro).

Em uma festa pública dedicada ao Orixá Oxóssi, pessoas se reuniam para homenagear os orixás presentes na festa. As energias sagradas evocadas nesse contexto interrogam a lógica binária, eurocêntrica e cristã que nos fora imposta diante da colonização.

A começar pelo transe em orixá, pois adeptos da religião acreditam que os orixás, forças míticas da natureza, podem ser manifestados em corpos humanos na condição de transe, e essa manifestação

\footnotetext{
${ }^{14}$ A esse respeito, ver Souza (2016, p.20): O sucesso do processo de colonização, ao longo dos séculos, estrutura-se na naturalização das relações sociais; desde muito cedo fomos condicionados às compreensões maniqueístas de mundo, tratando como sinônimos diferença e desigualdade. As relações sociais foram e ainda permanecem polarizadas, por isso fortalecem a concepção de superioridade, criando sentenças de inferioridade; assim como o colonizador impôs-se sobre o colonizado, ancorando-se em violências de todas as ordens: físicas, psicológicas, simbólicas, dentre outras. Para Oliveira et al. (2014, p.114): "A razão metonímica silencia diversas experiências sociais e conforma lógicas de produção de não existência (o ignorante, o residual, o inferior, o local e o improdutivo). A razão indolente, em contexto colonial, subjaz ao que os pesquisadores latino - americanos [...] denominam colonialidade do poder".

Para Santos (2010, p.32), "O pensamento moderno é um pensamento abissal". Tal abismo é desencadeado na polarização binária entre a existência e a inexistência, ou ainda, entre o humano e o não humano. A polarização das relações sociais tem como seu eixo estruturante e norteador a reflexão abissal, que desencadeia na criação de sentenças que transformam diferenças em desigualdades.
} 
independe do sexo de nascimento do individuo, ou mesmo de sua orientação sexual ou identidade de gênero.

Assim, é possível haver yao ${ }^{15}$ homem (hetero, homo, cis, trans...) que manifeste em seu corpo uma energia considerada feminina como uma yaba, por exemplo, um homem que entre em transe em Iemanjá; ou ainda, uma mulher (hetero, homo, cis, trans...) que se manifeste em Xângo, etc. Todas as variáveis são possíveis no transe em orixá.

Considerando que orixá é uma força mítica da natureza, é possível traçar algumas considerações com as reflexões de Butler (2000, p.151), que destaca "O corpo como tal não pode ser pensado e eu, certamente, não posso acessá-lo [...] Não existe natureza alguma, apenas efeitos de natureza: desnaturalização ou naturalização...”.

Contudo, na cosmologia de mundo Yorubá, não é possível pensar apenas o binarismo entre macho e fêmea, mas também não é possível considerar a inexistência da natureza, mas é correto afirmar que não há limites das diversas manifestações e possibilidades da natureza.

Essa afirmação da inexistência de limites às diversas manifestações da natureza - que aqui podem ser tomadas tanto como ausência de limites na manifestação da presença do orixá no corpo de um iniciado quanto na inexistência de limites estanques no exercício da sexualidade e na assunção de diferentes identidades de gênero.

Voltando ao diálogo das crianças no terreiro, a acusação de "viado", por parte de uma das crianças, dispensada àquele que queria brincar de boneca, contrasta. Podemos constatar então um duplo tratamento à mesma realidade: um manifestado no espaço privado (sala de jogos) e outro no público (barracão). Conforme já mencionado, esse tipo de dupla conduta é típico de uma mentalidade colonizada, resultante de uma situação colonial pregressa. E tal situação, por mais que seja problematizada, subsiste, mesmo que de forma residual, nas condutas adotadas pelos sujeitos implicados nessas questões, como é o caso das crianças às quais estamos aludindo. E isso se choca com a perspectiva yorubá afro-diaspórica.

$\mathrm{Na}$ perspectiva de mundo yorubá afro-diaspórica, quanto à questão de gênero não binária ou dicotômica, como no mundo euro-cristão, cabe destacar quenem existe "divisão", senão uma conjunção quartenária, cuja sintaxe organiza as categorias "aborô", correspondente ao princípio masculino; "iyabá", ao princípio feminino; "metá-metá", o princípio que circula simultaneamente pelos dois primeiros, e "laíibalopô", que é o princípio que se coloca para fora e além de qualquer perspectiva sexual e de gênero, diferente, contudo, da categoria "assexuado", de matriz ocidental.

Assim, por exemplo, a representação do tipo Ogum é aborô, Oxum é iyabá, Oxumarê é metámetá e Olorum (princípio criador) é laíibalopô. É essa organização quartenária e complementar que pode inviabilizar a criação de discursos fóbicos e sexistas, pois todas as possibilidades de enquadramento de

${ }^{15}$ O termo "yao" em Yorubá significa esposa, e é utilizado independente do sexo do adepto, designa pessoa iniciada em Orixá que entra em transe. No seu uso e sentido êmico, "yaô" nem implica e nem condiciona sexo, gênero ou orientação sexual. Contudo, no plano das relações sociais estabelecidas pelas populações de terreiro, muitas vezes a condição de yaô é associada à passividade sexual, o que levaria as pessoas nessa condição a sempre estarem sob suspeita dessa passividade, suspeita essa que na maioria das vezes recai sobre as mulheres e os homossexuais masculinos. 
gênero estão previstas nos mitos de origem, o que naturaliza a existência da diversidade e sua legitimidade, de modo a dificultar qualquer espécie de segregação ou de transformação de diferença em desigualdade.

Voltando à sala de jogos - portanto, ao espaço privado do terreiro e ao discurso binário e conflitante dos meninos, cabe destacar que a divisão de tarefas de acordo com os gêneros está presente em todas as civilizações, porém, o que não se tem no candomblé é a obstrução do protagonismo dessas categorias, pois elas são complementares (paratáxicas) e não excludentes ou construídas a partir da relação de subordinante e de subordinado (hipotáxica). Entretanto, independente da cosmologia de mundo quartecenária em relação ao gênero e nem mesmo o maior posto do terreiro ser ocupado por um homossexual, a relação binária e de subalternidade se fez presente no discurso das crianças.

\section{Tentativas de aproximações entre meninos e meninas}

Ao observarmos com atenção o início do episódio, há um menino, Pedro, convidando outro para brincar com as meninas e as bonecas, ou seja, naturalmente queriam brincar juntos. Aliás, quando Souza (2016) traça alguns dos objetivos da pesquisa, uma ponderação das crianças é a respeitodo coletivo, as crianças mostraram à pesquisadora que não era possível separar quem morava no terreiro das que iam apenas como visita ao candomblé.

Mesmo com Luara e Pedro propondo aproximações e o discurso do espaço favorecendo a integração, Iago, para se afirmar, nega esta possibilidade e Pedro, por sua vez, reforça um indicativo de inferiorização à condição de homossexualidade. Conforme Louro (2000, p.18): “A produção da heterossexualidade é acompanhada pela rejeição da homossexualidade. Uma rejeição que se expressa, muitas vezes, por declarada homofobia". Neste sentido, sempre que se recorre à homofobia como dispositivo de afirmação da heterossexualidade, está-se firmando uma identidade à base de uma afirmação contrastiva que pode, inclusive, originar um subproduto dessas construções identitárias, subproduto esse que se caracteriza pela violência e negação do outro. Considerando essas dinâmicas nos espaços dos terreiros e do candomblé, percebe-se um movimento dissonante em relação ao discurso mais comum, que é o do respeito à diferença e inclusão da alteridade.

Cabe destacar que romper com a relação binária de gênero existente em nossa sociedade não é uma atribuição do candomblé, mas, neste artigo, enfatizamos as práticas sociais de culturais infantis produzidas nesse espaço, e miramos para como as experiências de infâncias no contexto podem corroborar com a construção de uma educação igualitária. Contudo, os dados de Souza (2016) apontam que a relação de gênero é a que se apresenta com mais equívocos e distorções nas práticas sociais de culturas infantis das crianças do contexto.

Neste sentido, Araújo (2017), ao pesquisar notícias a respeitoda intolerância religiosa na Educação Básica, destaca uma série de eventos em diferentes regiões do país. Em um dos casos analisados (ARAÚJO, 2017, p. 250-253), um grupo de alunos evangélicos de uma escola estadual de Manaus, diante da proposta da coordenação da escola para a realização de uma mostra cultural, na qual se discutiria 
cultura afro-brasileira e indígena - projeto esse fundamentado nas leis federais 10.639/2003 e 11.645/2008 - se posicionou contra a realização do projeto, alegando, dentre outros aspectos, que os temas levariam a uma apologia à umbanda, ao candomblé, à prostituição e à homossexualidade.

Nesse caso específico, ao aproximar essas religiões da prostituição e da homossexualidade, aquela turma de alunos, mesmo que não tivesse consciência disso, estava reeditando um discurso estereotipado acerca de um continum, pretensamente existente, entre uma coisa e outra. Esse continum insinuado pelo grupo de alunos conservadores pode mesmo ser atribuído a essa forma não binária da sexualidade humana e das identidades de gênero existentes na maior parte dessas religiões. Contudo, entre aqueles alunos e as populações de terreiro há uma inversão de sinais no que se refere aos sentidos do não binarismo. Enquanto nos terreiros a multiplicidade de possibilidades é vista como algo positivo e bem-vindo, entre os alunos daquela escola de Manaus o não binarismo é considerado perigoso à sua fé e às suas convicções. Foi pautado nessa compreensão que aquele grupo alegou objeção de consciência, recusou-se a desenvolver a proposta da coordenação pedagógica, e terminou criando sua própria proposta e desenvolvendo outro projeto, cujo título era "Missões na África". Ainda nesse caso, há de se observar o viés homofóbico que permeia a performance dos alunos de Manaus. Essa mesma homofobia também é verificada nas crianças do IbáLatan, naquele momento em que as crianças estão no espaço privado. Talvez aqui possamos analisar os efeitos dos diferentes espaços (público e privado) nas performances dos atores sociais. No terreiro, é como se houvesse assuntos que só podem vir à tona quando no espaço privado. Já na escola, considerando os principais protagonistas da situação, há uma performance que, ou confunde público e privado, ou, de fato, está se posicionando de acordo com uma mentalidade naturalizada, que rejeita qualquer aproximação com outra possibilidade de compreensão da sexualidade e das identidades de gênero que não seja aquela binária, ratificada por suas comunidades religiosas.

O caso de Manaus, contudo, não está isolado. Há, pelo país inteiro, casos em que aluno/as e familiares se recusam a qualquer abordagem a respeitodas religiões de matriz africana, associando-as à homossexualidade e à prostituição.

Como se pode constatar, a colonização patriarcal de nossos sentidos atravessa não só os muros dos terreiros, como a autonomia didática dos professores/as da Educação Básica. Se em seu livre brincar e na construção de suas culturas as crianças reproduzem discursos homofóbicos, em outra região, em uma escola, adolescentes associam as religiões de matriz africana à homossexualidade. Pode-se, então, problematizar o papel desses diferentes espaços de vivências e construção de saberes (a escola e o terreiro) na formação das mentalidades e condutas dessas crianças e jovens. É possível questionar, inclusive, até que ponto reproduzem discursos e mentalidades existentes nos seus círculos de convivências exteriores a esses espaços. Essas formas de corresponder a determinadas expectativas por meio da aceitação ou rejeição da diferença que evocam nossos sentidos são atravessadas por essas dinâmicas e, justamente por isso, devem estar sempre atentos a esse tipo de construção. 
Esse atravessar de nossos sentidos é marcado pela violência da colonização, associamos equivocamente a normalidade ao padrão masculino, adulto, cristão, heterossexual, quando a compreensão humana implica possibilidades diversas de ser até para a permanência de sua existência.

Especialmente a relação humana com a natureza implica conceber o todo e não as partes, o múltiplo e não o uno. Tal violência se explicita nos xingamentos das crianças e na recusa dos adolescentes. Assim, há uma tentativa de marca colonial de alocar nesse padrão acima descrito, ou seja, todos que estão fora da polaridade que estabelece o homem, adulto, cristão e heterossexual.

Por isso, é necessário superar a ilusão de que ao abordarmos de forma positiva a discriminação vivenciada por algum grupo (negros, pobres, mulheres, homossexuais, idosos, crianças, etc) preparamos ou ao menos sensibilizamos os envolvidos para as demais discriminações. O discurso das crianças mostra que tal discurso nos revela a dureza da realidade, ainda que o espaço favoreça o acolhimento das questões raciais, sexuais, econômicas, etárias e de gênero. Fica explícito que a demarcação de espaços de poder perpassa pelo gênero e pela orientação sexual. Assim:

Muitos consideram que a sexualidade é algo que todos nós, mulheres e homens, possuímos "naturalmente". Aceitando essa idéia, fica sem sentido argumentar a respeito de sua dimensão social e política ou a respeito de seu caráter construído. A sexualidade seria algo "dado" pela natureza, inerente ao ser humano. Tal concepção usualmente se ancora no corpo e na suposição de que todos vivemos nossos corpos, universalmente, da mesma forma. No entanto, podemos entender que a sexualidade envolve rituais, linguagens, fantasias, representações, símbolos, convenções... Processos profundamente culturais e plurais. Nessa perspectiva, nada há de exclusivamente "natural" nesse terreno, a começar pela própria concepção de corpo, ou mesmo de natureza. Através de processos culturais, definimos o que é - ou não - natural; produzimos e transformamos a natureza e a biologia e, conseqüentemente, as tornamos históricas. Os corpos ganham sentido socialmente. A inscrição dos gêneros — feminino ou masculino - nos corpos é feita, sempre, no contexto de uma determinada cultura e, portanto, com as marcas dessa cultura. As possibilidades da sexualidade - das formas de expressar os desejos e prazeres - também são sempre socialmente estabelecidas e codificadas. As identidades de gênero e sexuais são, portanto, compostas e definidas por relações sociais, elas são moldadas pelas redes de poder de uma sociedade. (LOURO, 2000, p. 5-6)

As tentativas de aproximações entre meninas e meninos são atravessadas pela polaridade e pelo binarismo que envolve as relações de gênero e sexualidade. Assim, o candomblé divide as funções religiosas entre masculino e feminino; por exemplo, o cargo de ogã, mencionado por Pedro, é de fato um cargo masculino, o que não implica necessariamente a orientação sexual, mas são atividades demarcadas para os homens. E o cargo de ekede é exclusivo para mulheres. O comportamento de se dividirem por gênero é presenciado na sociedade e na religião; certamente essas relações exercem influência no comportamento apresentado pelas crianças. Mas, no caso do candomblé, não há relação de superioridade entre os cargos masculinos e femininos, por exemplo.

Contudo, a sociedade adultocêntrica espera que as meninas sejam de um jeito e que os meninos sejam de outro, e impõe padrões binários que estabelecem hierarquias entre crianças; afinal, meninos ou meninas são crianças que precisam e querem brincar, quer seja em espaços públicos ou privados. 
Finco (2010), ao observar as brincadeiras de meninos e meninas, revelouque as relações ocorridas na escola pesquisada podem ser consideradas momentos importantes para se construir uma relação não hierárquica, uma relação de respeito entre os gêneros. Deste modo, a professora tem papel fundamental para que essas relações possam acontecer de forma livre, sem cobranças quanto a um papel sexual prédeterminado.

O olhar para as questões da construção de gênero na infância de meninas e meninos, vivenciadas em um espaço coletivo e público de educação infantil, evidenciou os modos de ser; desejos e escolhas; vontades e fazeres; conflitos e alegrias; encontros e desencontros [...] a pesquisa buscou evidenciar a suposta neutralidade das práticas educativas na Educação Infantil carrega uma intencionalidade pedagógica, na organização dos tempos, espaços e brincadeiras revela-se o conhecimento e a construção teórica subjacentes nas práticas educativas das professoras, tais como a explicação das diferenças baseadas na Biologia e na Genética e a compreensão da identidade de gênero das crianças como estática e universal (FINCO, 2010, p.171).

No espaço coletivo público da Educação Infantil, é necessário romper com a demarcação binária de gênero, que não só desvaloriza um princípio religioso da cosmologia de mundo afro-diaspórica, como impede a construção de relações equânimes que garantam o direito das crianças de serem crianças e expressarem-se livremente.

\section{Construindo pedagogias descolonizadoras com as crianças}

Ainda "gerundiando", tentamos seguir construindo com as crianças alguns caminhos que possam nos orientar a elaborar práticas pedagógicas equânimes, por isso, voltamos às nossas percepções para as brincadeiras livres das crianças em uma casa de candomblé. Conforme orienta Gobbi (2010, p.2):

Explorar e conhecer linguagens utilizadas pelas crianças para expressarem se, bem como, aquelas usadas pelos adultos, significa estar junto com elas e perceber suas características de acordo com gênero, classe social, etnia, faixa etária a qual pertencem. Quem são mesmo? Estão em constantes e profundas relações com seus pares de idades iguais e diferentes em confrontos de ideias e negociações que geram criações coletivas e individuais. Para os adultos implica, a partir das incertezas - também proveitosas -, buscar a garantia de que diferentes pontos de vista sejam compreendidos, e que a escuta e o diálogo permaneçam presentes constantemente nos espaços de educação e cuidado destinados a primeira infância. As manifestações linguageiras das crianças e dos artistas convidam a reorganizar o mundo e experimentá-lo em outras versões, mediados pelos corpos que se mexem, que nem sempre falam com palavras e letras, mas que tanto dizem, provocando a conhecer o desconhecido ao mesmo tempo em que se constroem outros lugares de experiências, estranhando e conhecendo a todo instante.

Para Souza (2016), as crianças seguem uma lógica exúlica16; tal orixá traz, em seu arquétipo, a ordem e a desordem; uma de suas passagens mais conhecidas mostra que ele subverte a lógica de tempo e

\footnotetext{
${ }^{16}$ Exúlica, derivativo da palavra Exu. A esse respeito ver: Santos (2012, p. 140-141), a análise de Èsù se impõe como imprescindível para a compreensão da ação ritual e do sistema como totalidade. De fato, Ėsù não só está relacionado com os ancestrais femininos e masculinos e com suas representações coletivas, mas ele também é um elemento constitutivo, na realidade o elemento dinâmico, não só de todos os seres sobrenaturais, como também de tudo o que existe. Nesse sentido, como Olórun, a entidade suprema protomatéria do universo, Ėsù não pode ser isolado ou classificado em nenhuma categoria. É um princípio e, como o àse que ele representa e transporta, participa forçosamente de tudo. Princípio dinâmico e de expansão de tudo o que existe, sem ele todos os elementos do sistema e seu devir ficariam imobilizados, a vida não se desenvolveria. Segundo as próprias palavras de Ifá, "cada um tem seu próprio Ėsù e seu próprio Olórun, em seu corpo", ou "cada ser humano tem seu Èsù individual, cada cidade, cada casa (linhagem), cada entidade, cada coisa e cada sertem seu próprio Èsù", e mais, "se alguém não tivesse seu Ėsù em seu corpo, não poderia existir, não saberia que estava vivo, porque é compulsório que cada um tenha seu Èsù individual". Assim como
} 
espaço, pois "Exu matou um pássaro ontem com a pedra que hoje atirou". Similar a Exu são as criança, pois ambos criam a partir das palavras transformando estas em algo concreto, a criança vive a brincadeira e ao viver ela torna-se brincadeira e brinquedo, assim adultos viram objetos e objetos viram humanos, tudo depende das verdades por elas estabelecidas e acertadas em seus códigos próprios. Quem vive na fantasia são os adultos, estes sim estão presos a valores e têm padronizados e moldados os seus movimentos, os adultos acreditam ter o controle, o poder, o saber e com isso comprometem a sua capacidade epistemológica de expressar-se com o corpo e com os outros. Já as crianças têm Exu inscrito em sua lógica.

Talvez admitir a lógica exúlica seja complexo, pois implica admitir o nosso desconhecimento e os entraves limitantes do estado de adultez; mas, enquanto pesquisadoras/es das infâncias, somos unânimes em afirmar que devem ser criadas novas metodologias de escuta e compreensão das diferentes epistemologias trazidas pelas crianças.

Os resultados das pesquisas na área educacional (embora não escolar), em espaços coletivos de educação e cuidado, têm mostrado que as crianças pequenas de 0 a 6 anos são capazes de múltiplas relações, são portadoras de história, são produtoras de culturas infantis, são sujeitos de direitos. Ela é criança além de ser filha referendada no adulto. Assim, a infância, que não se esgota aos 6 anos de idade, é vista como uma fase da vida tão provisória (e concomitante) como as outras fases. Destacam-se, de forma híbrida, as metodologias não convencionais para investigar a pequena infância (FARIA, 2006, p.285)

As crianças seguem a lógica exúlica devorando e recriando tradições em um movimento de comer o mundo a sua volta; comem com os olhos, com o tato, com o olfato, com a audição, e seguem devorando por meio do outro, do colo, das saias, dos ombros, dos sorrisos e dos gestos que o corpo adulto pode alcançar para elas. E partilhando conhecimentos evoluem coletivamente, especialmente, porque, na lógica exúlica, presente no candomblé, a evolução se encontra no partilhar e não no acumular. Há uma circularidade implícita na lógica exúlica, e isso é o que traz pluralidade às epistemologias das crianças, pois para nos conectarmos com elas é exigido que nos transformemos, ou seja, mudemos a postura corporal à qual fomos habituados e doutrinados e passemos a olhar o mundo como se fosse a primeira vez que estivéssemos presentes nele, até porque a cada minuto o mundo se refaz. Assim, "gerundiando", afinal ele (o mundo) não é ele, como está sendo destacado no início do texto.

É olhando com as crianças que na cosmovisão afro-diaspórica encontramos a lógica exúlica, mas é experimentando mais do Brasil que talvez possamos encontrar tudo o que falta para a interpretação de tais epistemologias que nos soam estrangeiras. Assim:

Uma outra Pedagogia, portanto, se impõe: uma pedagogia da escuta, uma pedagogia das relações, uma pedagogia da diferença, o que chamei no meu doutorado de pedagogia macunaímica, onde além das ciências que a Pedagogia busca suas bases epistemológicas, também a arte é seu fundamento, garantindo assim a ausência de modelos rígidos preparatórios para a fase seguinte e, além de um cognitivismo característico das pedagogias, também a construção de todas as dimensões humanas e o convívio com a diferença, "sem nenhum caráter" (FARIA, 2006, p.286).

Olórun representa o princípio da existência genérica, Èsù é o princípio da existência diferenciada, em consequência de sua função de elemento dinâmico que o leva a propulsionar, a desenvolver, a mobilizar, a crescer, a transformar, a comunicar. 
Conforme destaca Faria (2006), sem nenhum caráter quer dizer, também, com todos os caráteres. E é com todas as crianças e com tudo das crianças que podemos de fato descolonizar, há que se pensar em uma pedagogia que se queira arteira, assim como Exu e como Macunaíma, ambos arteiros e por isso verdadeiros, legítimos e mais que brasileiros.

Buscando uma pedagogia que se quer arteira, visamos aprender com as crianças como é ser criança, como é se construir brincando, vivendo e, enfim, sendo. Assim, cabe destacar alguns conceitos orientadores para a construção de uma pedagogia arteira que apresenta posturas dinamizadoras da lógica exúlica:

a) Acolhimento: receber as crianças em sua ancestralidade dispostas a compreender suas epistemologias, isso exige na lógica exúlica romper com a noção de tempo e espaço, pois o mais velho não é necessariamente o mais experiente;

b) Cumplicidade: dispor o corpo para se colocar nos diferentes lugares com os outros, construindo com estes/as relações circulares pautadas, que implica na lógica exúlica em considerar que a infância trata-se de um estado e, por isso, pode um adulto ser infantil enquanto aprende-ensina-aprende, e pode ainda viver múltiplas infâncias em si mesmo na sua corporalidade;

c) Transformação: destinar com as crianças outras finalidades a ações e objetos não estabelecidas socialmente, considerando por meio da lógica exúlica o poder materializador das palavras, sendo esta sempre concreta independente da escrita, por isso há que se comprometer com o que se expressa seja ouvindo ou proferindo, através da oralidade.(SOUZA, 2016, p.34).

Para a pedagogia macunaímica de lógica exúlica, que reconhece as crianças arteiras como produtoras de culturas, o que interessa, de fato, é o que as crianças são, e não o que elas serão no futuro. Acolher as crianças em sua essência é papel da Educação Infantil; que os arquétipos de Exu e de Macunaíma nos permitam organizar as nossas percepções a respeito das infâncias e lembrarmos que as crianças já são.

Assim, conforme a epígrafe inicial, que nossas travessias sejam a nossa prioridade, e não o passado ou o futuro, simplesmente porque estes não são reais, certamente limitados (passado e futuro) como nós, os adultos, e ilimitado é o presente junto ás crianças. Por uma pedagogia mais arteira em que a prioridade seja a brincadeira.

\section{Referências}

ARAUJO, Patrício Carneiro. Entre o terreiro e a escola: lei 10.639/03 e a intolerância religiosa sob o olhar antropológico. Tese (Doutorado em Ciências Sociais) Pontifícia Universidade Católica, São Paulo, 2015.

BALANDIER, Georges. A noção da situação colonial. Cadernos de Campo USP. V. 3 n. 3, p. 107-133, São Paulo, 1993.

BRANDÃO, Gersonice Equede Sinha. Equede: A mãe de todos - Terreiro Casa Branca. Salvador: Barabô, 2015. 
BUTLER, Judith. Corpos que pensam sobre os limites discursivos do sexo. In: LOURO, Guacira Lopes. O corpo educado: pedagogias da sexualidade. Belo Horizonte: Autêntica, 2000.

FARIA, Ana Lúcia Goulart. Pequena infância, educação e gênero: subsídios para um estado da arte. Cadernos Pagu, v. 26, p. 279-287, Campinas, 2006.

FINCO, Daniela. Educação Infantil espaços e de confronto e convívio com as diferenças: análise da interação entre professoras e meninas e meninos que transgridem a fronteira de gênero. Tese (Doutorado em Educação). Universidade de São Paulo, São Paulo, 2010.

FREIRE, Paulo. Pedagogia da Esperança. São Paulo: Paz e Terra, 1997.

GOBBI, Márcia. Múltiplas linguagens de meninos e meninas na educação infantil. In: ISeminário Nacional Currículo em Movimento Perspectivas Atuais, 2010, Belo

Horizonte. Curriculo em Movimento e Perspectivas Atuais. Belo Horizonte: UFMG, 2010, v. 01.

HAMPATE BÂ, Amadou. Amkollel, o menino fula. Tradução Xina Smith de Vasconcellos. São Paulo: Casa das Áfricas e Pallas Athena, 2003.

A tradição viva. In: KI-ZERBO, J. História Geral da África - Metodologia e Pré-História da África. Brasilia: UNESCO, 2010.

LEITE, Fábio. A questão ancestral. São Paulo: Palas Athena \& Casa das Áfricas, , 2008.

SANTOS; MENESES (orgs). Epistemologias do Sul. São Paulo: Cortez, 2010.

SODRÉ, Muniz.O terreiro e a cidade: a forma social Negro-Brasileira. Rio de Janeiro: Vozes,2002.

SOUZA, Ellen de Lima. Experiências de infâncias com produções de culturas no Ilê Axé Omo OxéIbáLatam.Tese (Doutorado em Educação) - Universidade Federal de São Carlos, São Carlos, 2016.

VERGER, Pierre. Notas sobre o culto aos orixás e voduns na Bahia de todos os santos, no Brasil, e na antiga costa dos escravos, na África. Tradução: Carlos Eugênio Marcondes de Moura. São Paulo: Universidade de São Paulo, 1999.

: CARYBÉ, Hector Julio. Lendas Africanas dos Orixás. 4. ed. Salvador: Corrupio, 2011. 